\title{
ENERGY ANALYSIS OF PROPULSION SHAFT FATIGUE PROCESS IN ROTATING MECHANICAL SYSTEM \\ PART I \\ TESTING SIGNIFICANCE OF INFLUENCE OF SHAFT MATERIAL FATIGUE EXCITATION PARAMETERS
}

\author{
Zbigniew Korczewski \\ Konrad Marszałkowski \\ Gdańsk University of Technology, Poland
}

\begin{abstract}
The article discusses the problem of mathematical modelling of energy conversion processes in a rotating mechanical system for the purpose of identifying fatigue states of propulsion shafts in this system. A simplified physical model of the analysed system, constructed in an appropriate scale, has made the basis for the experimental research. The research programme took into consideration mechanical fatigue excitation of the model propulsion shaft to find the correlation between the dynamic system load generated by a bending moment and the energy state of a specified shaft segment. A physical model of the analysed process was proposed, for which the plan of static randomised block experiment was worked out. The recorded experimental results were used for statistical analysis of the significance of influence of the quantities exciting the propeller shaft fatigue process and the adequacy of the developed mathematical model describing shaft's durability. The analysis made use of the F-Snedecor test.

The article describes the general concept of the research, the constructed laboratory test rig, and the methodology of statistical inference concerning the significance of influence of input (exciting) parameters of the physical model on the recorded output parameters. The results of the performed statistical tests confirm the absence of the significance of influence of the rotational speed of the propulsion shaft on the selected types of rotating operation of the mechanical system. As a consequence, only one exciting parameter, which is the loading mass, is going to be taken into account in the functional description of fatigue life of the propulsion shaft.
\end{abstract}

Keywords: rotating mechanical system, modelling of energy processes, propulsion shaft fatigue, testing of statistical hypotheses

\section{INTRODUCTION}

A crucial condition for correct quantitative evaluation of energy related consequences of high cycle fatigue of the structural material of the propulsion shaft operating in the rotating mechanical system is developing an adequate mathematical model of unsteady and low-frequency physical processes taking place in the shaft. According to the theory of mathematical modelling and methods of experimental research planning, presented in $[1,7,11]$ among other publications, two ways of proceeding are possible, which are:

1. Deductive way: starting from the theoretical background of the modelled processes and adopting certain simplifying assumptions, equations are formulated which define relations between input and output signals (so-called balance equations), based on fundamental laws of physics (energy, momentum, angular momentum, and mass conservation laws, for instance). The mathematical model developed in the above way should undergo verification tests by comparing relevant results of numerical simulations of physical processes performed using this model with the results of experimental examination of a real object after introducing the same excitations. This way the adequacy of the model is assessed.

2. Inductive way: firstly, based on a precisely planned experiment the examination of a real object is performed. 
The time-histories of output signals are recorded for the assumed variations of input signals. The regression analysis of both types of signals makes the basis for defining mathematical relations between them. These relations are then subject to verification, according to the theory of testing of parametric statistical hypotheses.

Due to high structural complexity of rotating mechanical systems of real objects, the equations which describe their motion are very sophisticated, and a large number of assumptions simplifying the physical model of the analysed energy processes are to be adopted $[2,3]$. This makes the verification of correctness of the developed mathematical model very difficult, especially in the situation when the detailed information on the used structural materials (their mechanical and thermal characteristics) is missing. That is why a decision was made to apply the inductive approach to the identification of the propulsion shaft fatigue process in the rotating mechanical system, and to determine a general formula describing the influence of the bending moment load of the system on the energy state (and durability) of the specified shaft segment. However, this approach is not an obstacle in the identification research, as the rule applies in empirical sciences that examining arbitrary physical processes should start with developing their simplest models.

\section{CHARACTERISTICS OF OBJECT OF RESEARCH}

To model real energy processes taking place during the operation of the rotating mechanical system, a simplified physical model of this system was constructed in relevant scale to model structural and functional characteristics of the real object. For this purpose, the testing machine produced by Schenck was used. It was initially designed for tests oriented on assessing fatigue limits of structural materials subject to reverse bending - Fig. 1.

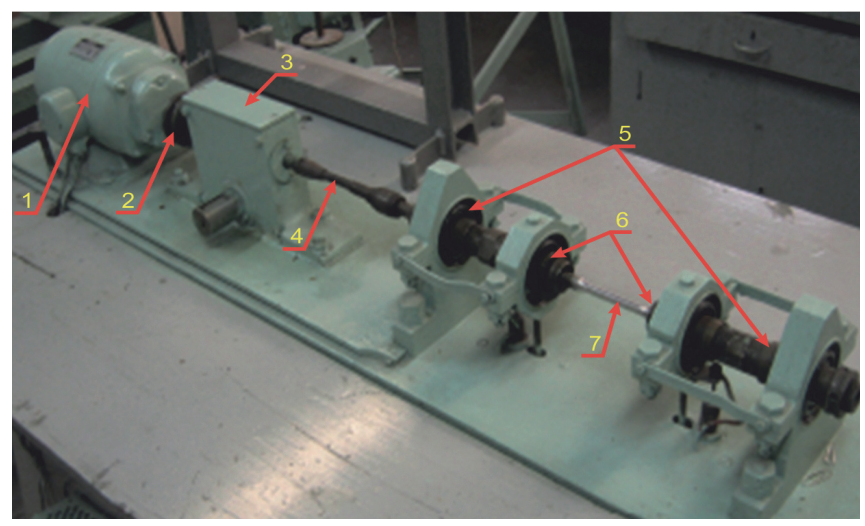

Fig. 1. Standard testing machine produced by Schenck for assessing the fatigue limit at reverse bending: 1 - propulsion motor (DC shunt motor); 2 - flexible disc coupling (with pins and rubber pads); 3 - cycle counter worm gear (transmission ratio 1:100); 4 - flexible spring coupling; 5 - fixed bearing bracket; 6 - mobile bearing bracket; 7 - tested sample
The fatigue cycle is executed on this machine by bending the rotating cylindrical sample of constant cross-section with constant load (loading mass $m_{o b c}$ ) situated in the same plane. The scheme of the physical model of the rotating mechanical system which executes this fatigue cycle is shown in Fig. 2. Acharacteristic feature of the machine used for these tests is no power take-off at the end of the propulsion line, while the basic advantage is uniform load distribution with the bendingtwisting moment along the entire length of the tested material sample. This way of modelling laboratory conditions in the fatigue test which take into account real operating conditions of a rotating mechanical system (ship propulsion unit, for instance), can simulate loss of coaxiality or bending of the shafting, which leads to the increase of pressure forces acting in bearings and the resultant increase of mechanical losses connected with friction in the shafting. Also for this reason, like in the full-scale propulsion system, the modernised Schenck's testing machine provides an option of rotational speed stabilisation by feeding the electric motor via a thyristor controller - Fig. 2.

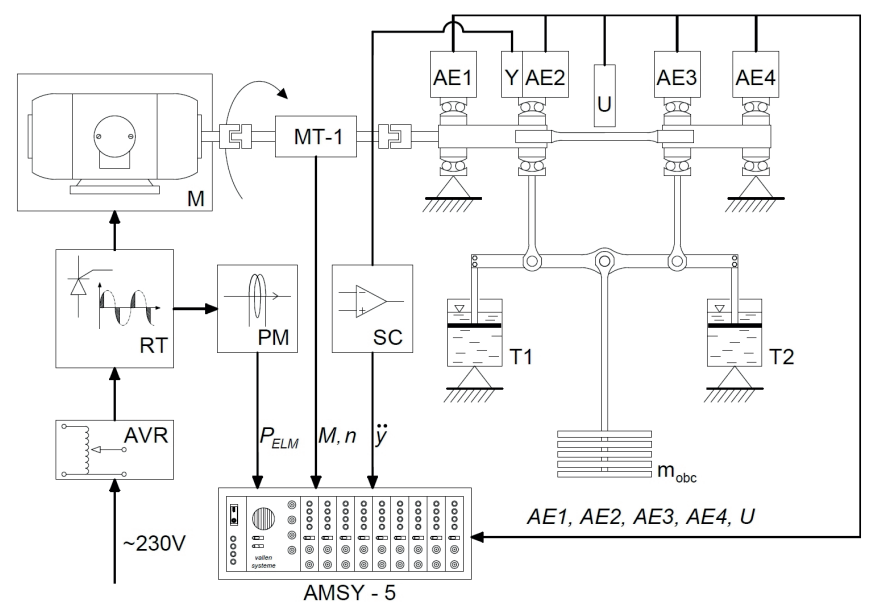

Fig. 2. Scheme of the physical model of the rotating mechanical system, with the distribution of measuring converters: $M$ - electric motor 0,25 $\mathrm{kW}$ $M T-1$ - torque meter; AE1-AE4 - acoustic emission converters; $Y$ - vibration acceleration converters; $U$ - sample deflection converter; $R T$ - thyristor rotational speed controller; AVR - network voltage stabiliser; $P M-$ measuring converter of electric power; $S C$ - conditioner of vibration acceleration converter signal; T1, T2 - oil dampers; $m_{\text {bc }}$ - loading mass. Recorded voltage signals: AE1, AE2, AE3, AE4 - acoustic emission; $U$-sample deflection; $M$ - torque; $n$ - rotational speed, $P_{E L M}$ - electric power taken by propulsion motor, $\ddot{y}$ - mechanical vibration acceleration

The unsteady mechanical energy balance of the tested system leads to fluctuations of the rotational speed of the propulsion line. Moreover, the consequences of the excited elastic and plastic deformations of the sample are: transverse vibration generated at bearing nodes, acoustic emission of a series of decaying elastic waves, and thermal emission (infrared radiation) of elements of the system accumulating the internal energy. Taking into consideration the above aspects, the already existing standard test rig had to be modified in such a way as to allow simultaneous, multi-symptom, energy related observation of the high-cycle fatigue process of the standard sample. The designed measuring system was expected to allow continuous recording of parameters 
characterising accumulation and dissipation of different forms of energy during the unsteady low-frequency process accompanying the properly planned fatigue test. For this purpose, the following measuring signals were recorded during the operation of the physical model:

- rotational speed and transmitted torque,

- deflection and temperature of the sample,

- mechanical vibration and acoustic emission (generated by bearing nodes),

- voltage and electric current supplying the electric motor. A detailed characteristic of the measuring system installed on the test rig was given in earlier publications by the authors $[8,9,10]$. A general view of the rig with the measuring equipment is shown in Fig. 3.

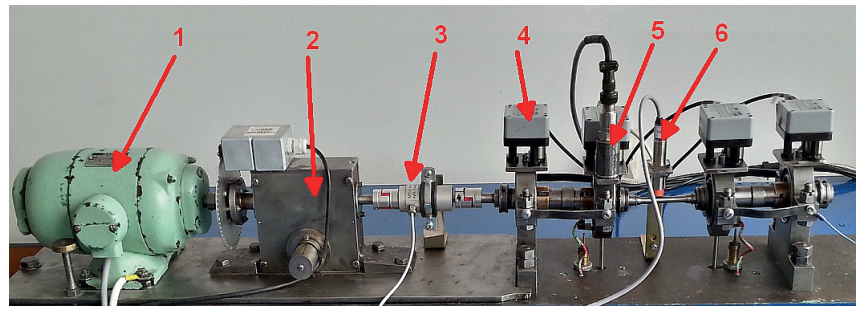

Fig. 3. General view of the test rig: 1 - electric motor; 2 - cycle counter worm gear; 3 - torque meter MT-1; 4 - acoustic emission converter; 5 - vibration acceleration converter; 6 - sample deflection converter

\section{MODELLING OF PROPULSION SHAFT FATIGUE PROCESS}

Modelling of the propulsion shaft fatigue process in the rotating mechanical system aims at determining the function which describes its durability. The independent variables in this function are energy parameters describing the action during transmission of mechanical energy and its conversion to work and heat forms $[5,6]$. In a descriptive sense, this operation can be interpreted as conversion of energy $E$ at given time $\tau$, which in formal approach can be expressed by the formula:

$$
D(\tau)=\int_{\tau_{1}}^{\tau_{2}} E(\tau) d \tau
$$

where:

$D(\tau) \quad$ - action at time $\tau[\mathrm{J} \cdot \mathrm{s}]$,

$\tau \quad-$ time $[\mathrm{s}]$,

$E(\tau) \quad$ - system energy at time $\tau[\mathrm{J}]$,

$\left[\tau_{1}, \tau_{2}\right]$ - time interval of operation.

Each energy parameter, expressed in joule-seconds, characterises the potential of the energy source, the measure of which is a number with unit of measurement [J.s] and the area bounded by: the graph of changes of energy (or its carrier), the time axis, and vertical lines representing the limits of integration $\tau=\tau_{1}$ and $\tau=\tau_{2}$ of the definite integral of function $E(\tau)$ given by formula (1). The limits of integration of this function, i.e. $\tau_{1}$ (lower) and $\tau_{2}$ (upper) are the time limits of the fatigue process observation - Fig. 4 .

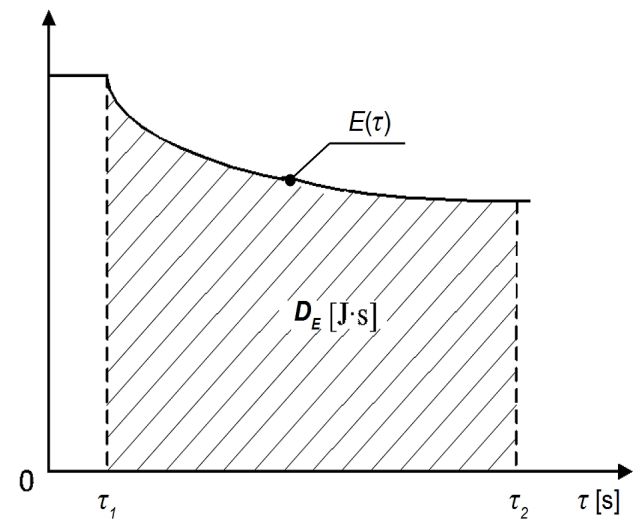

Fig. 4. Geometrical interpretation of the energy parameter characterising the potential of the energy source

Developing the mathematical model of the propulsion shaft (sample) fatigue process in the analysed mechanical system needs defining the physical model, in which the input parameters exciting the fatigue process in the conditions of really introduced deflection of the sample are determined along with the output and disturbance parameters - Fig. 5. It was assumed that the input (set) parameters in the modelled process are:

- mass loading the sample $-m_{o b c}$,

- rotational speed of the sample - $n$,

while the output parameters characterising the accumulating potential of the sample are:

- action related with conversion of mechanical energy to mechanical work form $-D_{W}$,

- action related with generation of mechanical vibration $-D_{V}$,

- action operation related with generation of elastic acoustic emission waves $-D_{E A}$,

- action operation related with conversion of mechanical energy to heat form $-D_{U}$.

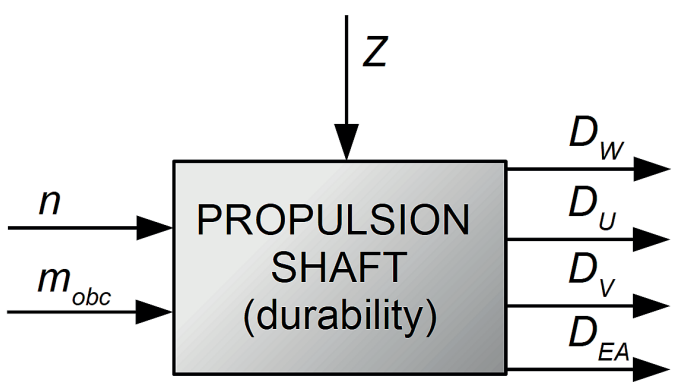

Fig. 5. Physical model of the propulsion shaft (sample) fatigue process in the rotating mechanical system

Basic disturbance parameters $(Z)$ which disturb the course of the modelled process include:

- environmental conditions (location of use of the tested physical model, environment parameters),

- non-homogeneousness and anisotropy of the structural material of the sample representing the propulsion shaft, - technical condition of bearing nodes. 
Since the tests were performed in similar ambient conditions (closed and air-conditioned room), the material samples were made from the same drown bar, and the bearing degradation was relatively small, an assumption was made [10] that the effect of disturbances is negligibly small.

\section{STATISTICAL ANALYSIS PROGRAMME}

As the first stage of identification of the propulsion shaft fatigue process in the rotating mechanical system, the eliminating statistical analysis was performed to determine the correlation between the adopted input parameters: $m_{o b c}$ and $n$, and output parameters $D_{W}, D_{V}, D_{E A}$ and $D_{U}$ of the physical model. The analysis was performed based on the randomised plan of active experiment, applicable for determining the influence of the progressive process of fatigue wear of propulsion shaft material, along with the execution ofsuccessive cycles of periodically changing stresses resulting from shaft deflection, on the analysed output parameter, which is the fatigue life of the shaft [13]. In the analysed fatigue problem, an assumption was made that this output parameter is defined by energy parameters characterising the operation of the examined mechanical system, while the influence of the set input parameters on it depends on the sequence of realisation of elements of the adopted plan of experiment. That is why the basis for randomisation of the plan of experiment is a random order of successive test executions for the a priori assumed variability levels of input parameters [11].

The values of input parameters $m_{o b c}$ and $n$ were assumed at three variability levels which guarantee feasibility of the experiment. In each measuring series, five repeated tests were performed. The plan of experiment is shown in Table 1.

The values of the rotational speed $n$ of the shaft and the loading mass $m_{o b c}$ which were adopted in the plan of experiment result from the observations made during preliminary studies. These observations enabled to assess the variability ranges of the parameters intended to excite the fatigue process. For the applied shaft material (structural steel C45), as well as for the given geometrical dimensions and capabilities of the test rig, the system mass load was assumed (provided) at the level of $25 \mathrm{~kg}$. Below this level, the shaft material reveals unlimited fatigue life in the bending-rotating test, which makes recording the fracture process impossible. On the other hand, the maximal excitation value is limited by static bending resistance of the material of the sample. The upper limit of the loading mass $m_{o b c}$ is equal to $45 \mathrm{~kg}$.

A similar relation was observed when analysing the variability range of the rotational speed of the shaft. In order to minimise disturbances of the mechanical stability of the test rig, the nominal rotational speed was assumed at the level of $n=1500 \mathrm{rpm}$. Below $n=1200 \mathrm{rpm}$ and above $800 \mathrm{rpm}$ the run of the fatigue machine is unsteady, which results from insufficient damping of mechanical vibration by oil dampers - Fig. 2.
Tab. 1. Plan of eliminating experiment

\begin{tabular}{|c|c|c|}
\hline No. & $\begin{array}{c}\text { Loading mass } \\
m_{\text {obc }}[\mathrm{kg}]\end{array}$ & $\begin{array}{c}\text { Rotational speed of shaft } \\
n[\mathrm{rpm}]\end{array}$ \\
\hline 1 & 40 & 1800 \\
\hline 2 & 35 & 1800 \\
\hline 3 & 30 & 1800 \\
\hline 4 & 40 & 1500 \\
\hline 5 & 35 & 1500 \\
\hline 6 & 30 & 1500 \\
\hline 7 & 40 & 1200 \\
\hline 8 & 35 & 1200 \\
\hline 9 & 30 & 1200 \\
\hline
\end{tabular}

Each time before the beginning of the experiment, the fatigue machine worked for about 30 minutes without sample loading to warm up the bearings and the motor. After this warm-up time, no significant changes in electric parameters of the motor and the transmitted torque were recorded. Additionally, at the beginning of data acquisition, the initial $100 \mathrm{~s}$ were always recorded as the sample run without loading, after which the loading mass was automatically released and the basic part of the test started. Selected representative results of a single fatigue test are shown in Fig. 6.

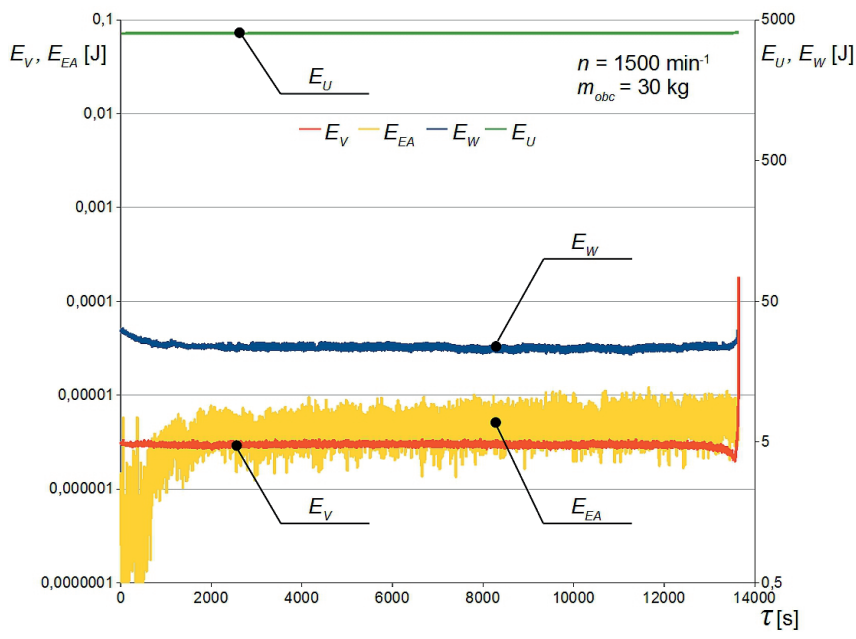

Fig. 6. Results of single fatigue test:

$E_{U}$ - internal energy of the system, $E_{w}$ - system energy related to mechanical work, $E_{E A}$ - energy of elastic acoustic emission waves, $E_{V}$ - energy of mechanical vibration, $\tau$ - time of the test

\section{MATHEMATICAL PROCESSING OF STATISTICAL TEST RESULTS}

A characteristic feature of material fatigue studies is high dispersion of results obtained in individual tests, which is mainly caused by material non-homogeneousness of samples and their manufacturing inaccuracy [14]. A similar conclusion can be formulated based on experimental tests performed by the authors. The observed dispersion in fatigue test duration (number of cycles) reached as much as $50 \%$. That is why a method had to be worked out to analyse test results in 
energy approach which would allow their comparison for different combinations of input parameters and examine their influence on output parameters. The result of each measuring sequence consisting of five repetitions is the arithmetic mean of operation values of the given system. Averaging reduces the number of results which need analysing from $\mathrm{z} 45$ to 9 .

The significance of the influence of input parameters on output parameter was verified using the parametric F-Snedecor test [9]. The null hypothesis formulated for this test assumes the absence of significant influence of two selected input parameters on four analysed output parameters. Mathematical processing of results of tests performed in accordance with the randomised static block plan consists in calculating the values of coefficients $F_{m o b c}$ and $F_{n}$ for each input parameter. The results of these calculations are compared with the critical value determined based on statistical tables of critical values of the F-Snedecor test for the assumed confidence level $\alpha$ and the number of degrees of freedom $f$. For the assumed confidence level $\alpha=0,05$ and the numbers of degrees of freedom $f_{1}=2, f_{2}=4$ the critical value of the F-S distribution is $F_{k r}=6,9443$. The influence of the analysed input parameter on output parameters is considered significant when the calculated test value of the given coefficient, $F_{\text {mobc }}$ or $F_{n}$, is greater than or equal to the critical value.

According to the adopted plan of experiment and the set of parameters selected for a given physical model, the significance of influence of input parameters on output parameters was verified. The results of statistical tests are given below.

\section{ACTION AS RESULT OF ENERGY CONVERSION TO WORK FORM}

The performed experiment allowed to determine the action related with mechanical energy conversion and the resultant mechanical work, $D_{W}$. The rotational speed of the shaft was recorded along with the transmitted torque. This allowed to calculate the instantaneous work values in the rotational motion which were related with the fatigue process excitation. The obtained time-history of work, being the form of energy conversion as a function of time, was used for determining the action for each test, via integration performed with the aid of the trapezoidal rule (according to formula 1). The averaged action values related with mechanical energy conversion to mechanical work form are collated in Table 2 for different combinations of input values.

Tab. 2. Action values related with execution of mechanical work, DW [J.s]

\begin{tabular}{|c|c|c|c|}
\hline \multirow{2}{*}{$\begin{array}{c}m_{o b c} \\
{[\mathrm{~kg}]}\end{array}$} & 1200 & 1500 & 1800 \\
\cline { 2 - 4 } & 306946,69 & 260594,36 & 205767,71 \\
\hline 30 & $152235,22 \mathrm{~J}$ & 109525,1 & 128929,16 \\
\hline 35 & 98334,2 & 45447,12 & 51010,87 \\
\hline 40 & &
\end{tabular}

The coefficients $F_{n}$ and $F_{m o b c}$ calculated for the input parameters: rotational speed and loading mass, are equal to 5,3081 and 54,5366, respectively. Since the value of coefficient $F_{n}$ is smaller than the critical value $\left(F_{k r}=6,9443\right)$ we can assume that there is no significant influence of this input parameter on the action related with execution of mechanical work.

\section{ACTION AS RESULT OF ENERGY CONVERSION TO HEAT FORM}

Studying the action related with heat emission $D_{U}$ consisted in the qualitative and quantitative analysis of thermographic images of the cyclically loaded shaft. The recorded thermograms were used for determining, with 100 s intervals, instantaneous internal energy values of the specified shaft segment. Changes of these values resulted from mechanical energy conversion to heat form. Since the highest shaft temperature rise recorded during all tests was equal to $\Delta T=25 \mathrm{~K}$, the specific heat value of the structural material of the shaft was assumed constant and equal to $c_{p}=470 \mathrm{~J} /$ $\mathrm{kg} \cdot \mathrm{K}$ during the entire experiment. The mass of the specified shaft segment was $m_{p}=0,028 \mathrm{~kg}$. The recorded time-history of changes of internal energy of the shaft during the fatigue test was used to determine, via numerical integration, the action related with mechanical energy conversion to heat form. The averaged action values related with heat emission are given in Table 3.

Tab. 3. Action values related with heat emission, DU [J.s]

\begin{tabular}{|c|c|c|c|}
\hline \multirow{2}{*}{$\begin{array}{c}m_{o b c} \\
{[\mathrm{~kg}]}\end{array}$} & 1200 & 1500 & 1800 \\
\cline { 2 - 4 } & 43662499,46 & 42843494,45 & 38502003,54 \\
\hline 30 & 25576545,13 & 24671248,06 & 21349759,43 \\
\hline 35 & 17481255,6 & 8266451,78 & 8019399,83 \\
\hline 40 & & & \multicolumn{3}{|c|}{$n$} \\
\hline
\end{tabular}

The coefficients $F_{n}$ and $F_{m o b c}$ calculated for the input parameters: rotational speed and loading mass, are equal to 5,0334 and 118,0695, respectively. Like for the action related with mechanical energy conversion to work form, also in this case no significant influence of the rotational speed of the propulsion shaft on the action related with heat emission was detected.

\section{ACTION MODELLED IN THE VIBRATION PROCESS}

The action related with generation of mechanical vibration, $D_{V}$ was assessed based on the recorded time-histories of deflection (vibration) of the geometrical shaft centre. These time-histories were differentiated numerically to determine the speed of transverse vibration. Then the RMS value of the vibration speed was calculated (square averaging) for every second of the test. The amount of kinetic energy dissipated in the form of mechanical vibration during the rotational motion of the shaft is always a function of the square of vibration speed 
$[8,9,10]$. Therefore, for each one-second interval, the amount of energy dissipated in the form of mechanical vibration was calculated as the product of mass and the square of RMS value of vibration speed. Like in previous cases of energy conversion, the time-histories of propulsion shaft transverse vibration energy changes, obtained in the above way, were integrated numerically to determine the action related with vibration generation. The averaged values of action $D_{V}$ for constant values of input parameters are given in Table 4.

Tab. 4. Action values related with generation of mechanical vibration, $D_{V}[J \cdot s]$

\begin{tabular}{|c|c|c|c|}
\hline \multirow{2}{*}{$\begin{array}{c}m_{\text {obc }} \\
{[\mathrm{kg}]}\end{array}$} & 1200 & 1500 & 1800 \\
\cline { 2 - 4 } & 0,079332578 & 0,047725485 & 0,075701043 \\
\hline 30 & 0,062292588 & 0,0041851675 & 0,018446676 \\
\hline 35 & 0,020791802 & 0,01073448 & 0,005595129 \\
\hline 40 &
\end{tabular}

The coefficients $F_{n}$ and $F_{m o b c}$ calculated for the input parameters: rotational speed and loading mass, are equal to 3,9590 and 11,3140, respectively. Like in previous cases, also in this case no significant influence of the rotational speed of the propulsion shaft on the action related with generation of mechanical vibration was detected.

\section{ACTION MODELLED IN ACOUSTIC EMISSION}

The fatigue life of the propulsion shaft can also be characterised by the action related with generation of elastic acoustic emission waves, $D_{E A}$. The mechanical (kinetic) energy dissipated in the form of elastic acoustic emission waves is expressed in the apparatus AMSY-5 in the form of arbitrary units (so-called eu units) introduced by the apparatus producer [15]. Since the developed model is expected to return not only qualitative but also quantitative results, the real amount of energy dissipated in the form of elastic acoustic emission waves was to be determined. The measuring lines of the acoustic emission sensors were calibrated using the method in which the elastic wave was released in the material by dropping a small steel ball [12]. This method allows to determine this part of energy of the falling ball which is converted to elastic energy of the material on which the ball falls. The energy of elastic deformation is entirely converted to the energy of elastic waves. In an auxiliary experiment, the ball with mass of $0,00105 \mathrm{~kg}$ was dropped from three heights: 10,20 and $30 \mathrm{~mm}$, onto the hardened plate made of NC10 steel. The differences between the dropping height and the rebound height were used to determine the amount of potential energy converted to the elastic wave energy. The relation between the dropping height and the amount of the recorded energy is linear within this range, therefore one correction value equal to: $1 \mathrm{eu}=0,00000036916 \mathrm{~J}$ was used for calibration. The averaged action values related with generation of elastic acoustic emission waves are given in Table 5.
Tab. 5. Action values related with generation of elastic acoustic mission waves, $D E A[J \cdot s]$

\begin{tabular}{|c|c|l|c|}
\hline \multirow{2}{*}{$\begin{array}{c}m_{o b c} \\
{[\mathrm{~kg}]}\end{array}$} & \multicolumn{3}{|c|}{$n\left[\mathrm{~min}^{-1}\right]$} \\
\cline { 2 - 4 } & 1200 & 1500 & 1800 \\
\hline 30 & 0,0107207904 & 0,0393590177 & 0,0247581099 \\
\hline 35 & 0,0038553507 & 0,0147507758 & 0,0118168544 \\
\hline 40 & 0,0023520564 & 0,0012492075 & 0,0035523067 \\
\hline
\end{tabular}

The coefficients $F_{n}$ and $F_{m o b c}$ calculated for the input parameters: rotational speed and loading mass, are equal to 2,2030 and 6,9561, respectively. Also in this case no significant influence of the rotational speed of the propulsion shaft on the action related with generation of elastic acoustic emission waves was detected.

\section{FINAL REMARKS AND CONCLUSIONS}

It was assumed when analysing the significance of influence of the parameters exciting the propulsion shaft fatigue in the rotating mechanical system that the fatigue life of the shaft material depends on action. For the purpose of the above analysis, the operation of the mechanical system and the propulsion shaft was interpreted as energy conversion at given time. The operation interpreted in the above way was expressed by a number with the unit of measurement called joule-second [J.s].

Since no significant influence of the input parameter related with the rotational speed of the propulsion shaft on the selected types of action was detected (proved) in the performed analysis, the parameter related with the loading mass will be only taken into account in the developed functional description of the fatigue process. Consequently, a new plan of experiment needs to be worked out which will take into account the influence of only one input parameter. In this new plan, the resolution of loading mass changes is to be refined, this way providing more information on the course of the propulsion shaft fatigue degradation process. This information will be needed when preparing a new physical model of the rotating mechanical system.

As a further step, the theoretical model is to be made closer to the operating conditions of real objects by finding relations between the loading mass and real shaft deflection, and comparing these relations with the results of measurements obtained during diagnostic tests of watercraft shafting [4].

\section{BIBLIOGRAPHY}

1. Cannon R.H. (2003). Dynamics of physical systems. New York, Dover Publication.

2. Cempel C., Natke H.G. (2012). Model-aided diagnosis of mechanical systems: Fundamentals, detection, localization, assessment. Springer Science \& Business Media. 
3. Cichy M. (2001). Modelling of energy systems (in Polish). Gdansk, Wydawnictwo Politechniki Gdańskiej.

4. Dragantchev H. (2000). Control and diagnostics of ship shafting. Proceedings of the IMAM 2000, Ischia, 2-6 April, Session L, s. 115-122.

5. Girtler J. (2013). A method to evaluate operation of machines using technical diagnostics. Chapter 4, pp. 101-127, Monograph entitled "Diagnostic examination and inference. Selected issues" (in Polish). Warsaw, Wydawnictwo Wojskowej Akademii Technicznej.

6. Girtler J. (2015). Problems of rational use of diagnostic systems for decision making in power equipment operation phase, taking into account quantum issues. Chapter 5, pp. 91-123, Monograph entitled "Selected issues of diagnostics and use of devices and systems" (in Polish). Warsaw, Wydawnictwo Wojskowej Akademii Technicznej.

7. Gutenbaum J. (1992). Mathematical modelling of systems (in Polish). Warsaw, Instytut Badań Systemowych Polskiej Akademii Nauk.

8. Korczewski Z. (2012). The conception of energetic investigations of the multisymptom fatigue of the simple mechanical systems constructional materials. Journal of Polish CIMAC vol. 7 no 1 Energetic aspects. Gdansk, Wydawnictwo Politechniki Gdańskiej.

9. Korczewski Z. (2017). Operating diagnostics of marine internal combustion piston and turbine engines. Selected issues (in Polish). Gdansk. Wydawnictwo Politechniki Gdańskiej.

10. Korczewski Z., Marszałkowski K. (2016). Physical model of energy-related processes in a rotating mechanical system for the purposes of diagnosis of transmission shafts. Journal of Polish CIMEEAC, Vol. 11, No. 1.

11. Korzyński M. (2006). Methodology of experiment (in Polish). Warsaw, Wydawnictwa Naukowo-Techniczne.

12. Malecki I., Ranachowski J. (1994). Acoustic emission: sources, methods, applications (in Polish). Warsaw, Instytut Podstawowych Problem Techniki PAN.

13. Polański Z (1984).: Planning of experiments in engineering (in Polish). Warsaw PWN.

14. Szala J., Boroński D. (2008). Evaluating material fatigue state in diagnostics of machines and devices (in Polish). Bydgoszcz, Wydawnictwo Instytutu Technologii Eksploatacji - PIB.

15. VALLEN Systeme GmbH (2011). AMSY-5 System Specification.

\section{CONTACT WITH THE AUTHORS}

\author{
Zbigniew Korczewski \\ Konrad Marszałkowski \\ Gdańsk University of Technology, \\ Faculty of Ocean Engineering and Ship Technology \\ Department of Marine and Land Power Plants \\ 11/12 Narutowicza St. \\ 80-233 Gdansk \\ POLAND
}

